\title{
Mapping Soil Salinity in Western United Arab Emirates (UAE) Using Satellite Data
}

\author{
Abdelgadir Abuelgasim ${ }^{\mathrm{a}}$, Rubab Ammad ${ }^{\mathrm{b}}$ \\ ${ }^{a}$ Department of Geography and Urban Planning, College of Humanities and Social Sciences, United \\ Arab Emirates University, Al-Ain, Abu Dhabi 15551, UAE \\ ${ }^{b}$ Department of Biology, College of Science, United Arab Emirates University, Al-Ain, Abu Dhabi 15551, \\ $U A E$
}

\begin{abstract}
Soil salinity, whether natural or human induced, is a major geo-hazard in arid and semi-arid landscapes. In agricultural lands, it negatively affects plant growth, crop yields, whereas in semi-arid and arid nonagricultural areas it affects urban structures due to subsidence, corrosion and ground water quality, leading to further soil erosion and land degradation Accurately mapping soil salinity through remote sensing techniques has been an active area of research in the past few decades particularly for agricultural lands. Most of this research has focused on the utilization and development of salinity indices for properly mapping and identifying saline agricultural soils. This research study develops a soil salinity index and model using Landsat 8 OLI image data from the near infra-red and shortwave infra-red spectral information with emphasis on soil salinity mapping and assessment in non-agricultural desert arid and semi-arid surfaces. The developed index when integrated into a semi-empirical model outperformed in its soil salinity mapping overall accuracy $(60 \%)$ in comparison to other salinity indices $(\sim 50 \%)$. The newly developed index further outperformed other indices in its accuracy in mapping and identifying high saline soils (67\%) and excessively high saline soils (90\%).
\end{abstract}

Key words: Soil salinity, arid, semi-arid, Landsat 8 OLI

\section{Introduction}

Soil salinity is a major concern in the arid and semi- arid regions of the world and considered an environmental menace [1], [2] and [3]. It instigates the processes of soil erosion, dispersion and sometimes 
becomes a geo-hazard [4] by making the ground conditions unsuitable for construction due to subsidence, corrosion and low bearing capacity of saline soil, especially in case of "Sabkha (salt flats)." Unfortunately, most of the studies are based on the agricultural aspect of soil salinity and sabkha have largely been neglected despite having the highest grades of salinities, which will be addressed in this study.

Soil salinity is being studied world-wide over using various techniques and one of the most significant of them is satellite imagery as it is cost effective and time saving [5], simultaneously. Diverse types of satellite data are being utilized in various kinds of soil salinity studies with similar approaches. Remote sensing and GIS related approaches have been adopted by numerous scholarly works in attempts to study, map and model soil salinity in an effectively efficient way [6], [7], [8], [9] and [10]. The datasets used in these studies have variable resolutions and sources such as Landsat 8 [11], [12], [13], [14], Landsat Enhanced Thematic Mapper(ETM) and ETM+ [15], [16], [17], [18], IKONOS [19], [6], [7], IRS-1B LISS-II [5], MODIS [20], [21], [22], spectroradiometers [23], [24], [25] and others.

McBratney et al. (2003) [26] reviewed various techniques of modelling used in digital soil mapping, such as, linear and non-linear regression, neural networks, fuzzy systems, trend surfaces, and kriging [27],[28], [29]. Metternicht and Zinck (1997) [30] executed a synergistic design of mapping saline soils by coalescing the field characteristics of salt degraded soils, image classification and laboratory outcomes. Csillag et al. (1993) [23] and Farifteh et al. (2008) [24] attempted to identify the effects of salinization on the characteristics of spectral reflection in the lab by acquiring field samples and making their appropriate ratio solutions with deionized water and testing EC, and reflectance by spectrometer. (Csillag et al. 1993) [23] interpreted the data by means of revised stepwise principal component analysis (PCA), to improve the separability of various salinity states and consequently, recognizing crucial spectral ranges in the visible, NIR and SWIR parts of spectrum and six broad bands with in these ranges which showed high accuracy of salt identification. Additionally, [31], [32], [33], [27],[34] and [35] devised and tested various multiple indices comprising of spectral bands in different mathematical combinations to identify saline soils with an acceptable degree of accuracy. Moreover, (Masoud 2014) [18] in another scholarly work on Burg Al 
Arab, Egypt, carried out Spectral Mixture Analysis accompanied by Wetness Index to predict the salinity of the study area. ETM+ images were subjected to Mixture Tuned Matched Filtering (MTMF), Linear Spectral Un-mixing (LSU), and Spectral Angle Mapper with the result of high linear $\mathrm{R}^{2}$ values for MTMF, LSU and Wetness index. The authors also identified a strong negative relationship between reflectance and EC of the soil, maintaining that MTMF model was most suitable for salinity prediction.

Despite numerous leading-edge research on soil salinity study via remote sensing techniques, there is still no optimal combination of data set and the type of method which can be utilized in similar situations in order to yield almost matching results [27], [11]. Unfortunately, studies addressing soil salinity of open desert areas and sabkha are rather limited with few exceptions [36].

The primary objectives of this study are to address this limitation through the development of an empirical soil salinity reflectance model that is suited for open desert surfaces with scattered sabkha. The model is developed through regression analysis between soil spectral reflectance and field measured soil salinity values. Furthermore, the model will primarily utilize the NIR-SWIR regions of the electromagnetic spectrum which has received little attention in modeling soil salinity in comparison to the visible part. A comparative analysis between the developed model and other salinity empirical models is performed. 


\section{Study Area}

The study area lies in the western UAE, comprising of central and south-western parts of the state of Abu Dhabi, Figure 1. This geographical location is home to some of the largest sabkha surfaces in the world, including both coastal and inland sabkha found within a proximity of few kilometers from the coast. Sabkha

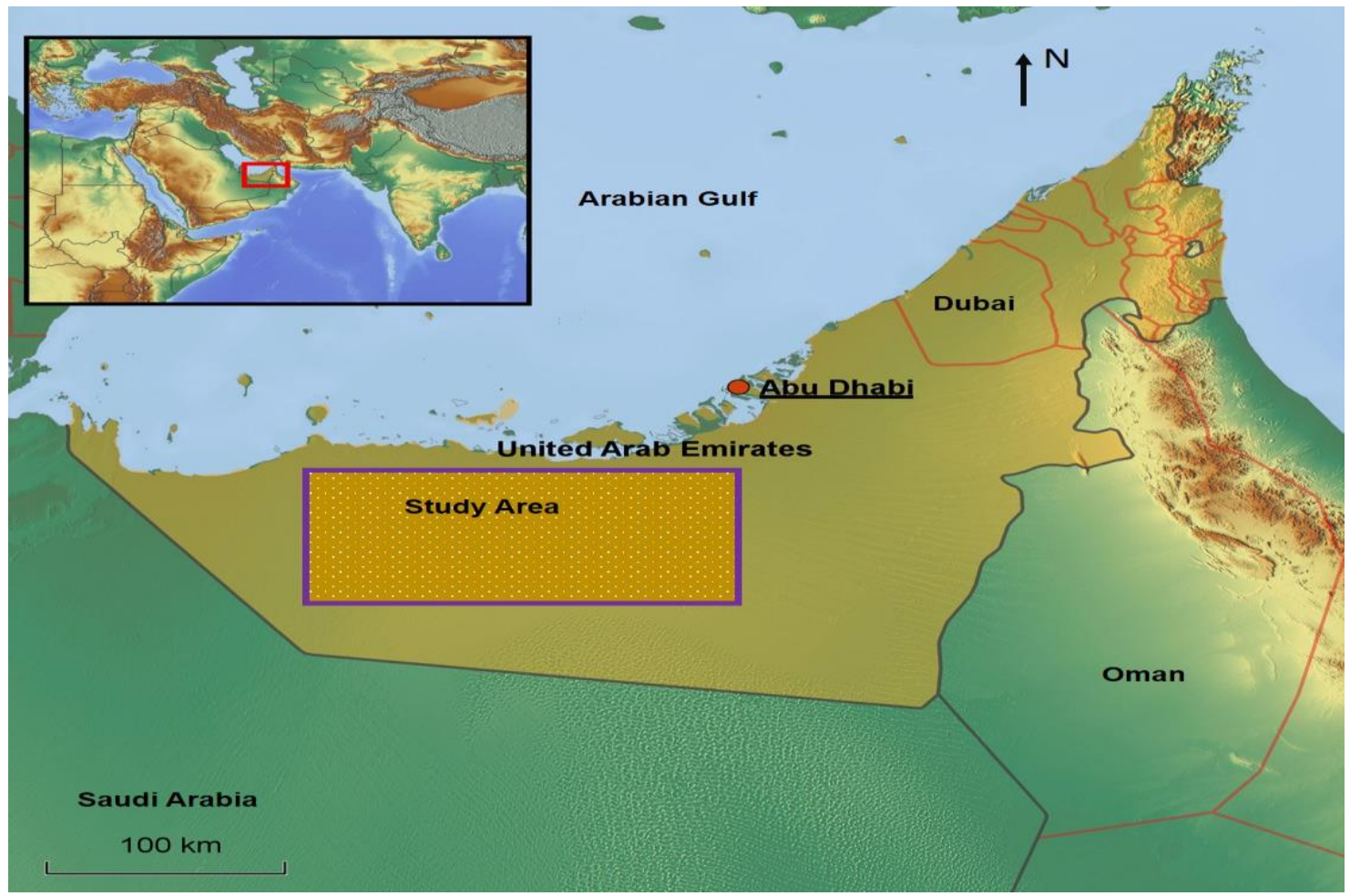

Figure 1: Study Area

are geologic features characterized by salt marshes and salt flats which are typically found in arid and semiarid climatic conditions, in shallow continental shelf/marine environment [37].

UAE with its extreme climatic conditions with minimum and maximum temperatures falling between $21.7^{\circ}$ $\mathrm{C}$ and $33^{\circ} \mathrm{C}$ respectively, provide a perfect environment for sabkha formation and hence is a home to large population of coastal and inland sabkha, distributed in various parts of the country.

The high rate of evaporation in these severely hot areas result in supersaturation of soil with insoluble salts leading to salt precipitation in enormous quantities, resulting in vast salt exposures. In the study area, sabkha 
pose a serious geotechnical threat as they are likely to, initiate cracks in surfaces because of uneven dehydration of gypsum, compromise soil strength, corrode steel due to presence of highly concentrated sulphate and chloride salts and lastly, crumble concrete owing to the crystallization pressure which built up as a response to evaporation of water [4].

The salt exposures can be identified on multispectral satellite imagery with the help of reflectance, which is believed to be affected by factors such as salt type, mineralogy, color and surface roughness [38]. Visible and near-infrared parts of spectrum are sensitive to saline soils and therefore, can be used to detect the former and sabkha alongside their spatial distribution and sizes.

\section{Field Measurements, Lab Analysis and Satellite Data}

\section{Field Measurements}

The soil sampling sites for the study were chosen, a priori, through the visual analysis of the satellite imagery within the study area. Sampling sites were carefully selected to allow ease of access in the tough desert terrain of the study area. Areas related to gas and oil production explorations were avoided.

In total 89 points were marked on the map for the collection of field samples, with emphasis on inland sabkha and adjacent presumed saline soil areas as shown in Figure 2. This is believed to allow the development of statistical empirical relationships between their respective salinities and the corresponding spectral reflectance. In all 59 points were chosen for the model development and 30 points for model and map verification. The field sampling process was carried out in November 2016 due to the extremely high temperature within the study area instead of the same time as the image acquisition date. Figure 3 shows some of the images from the sample collection sites. 


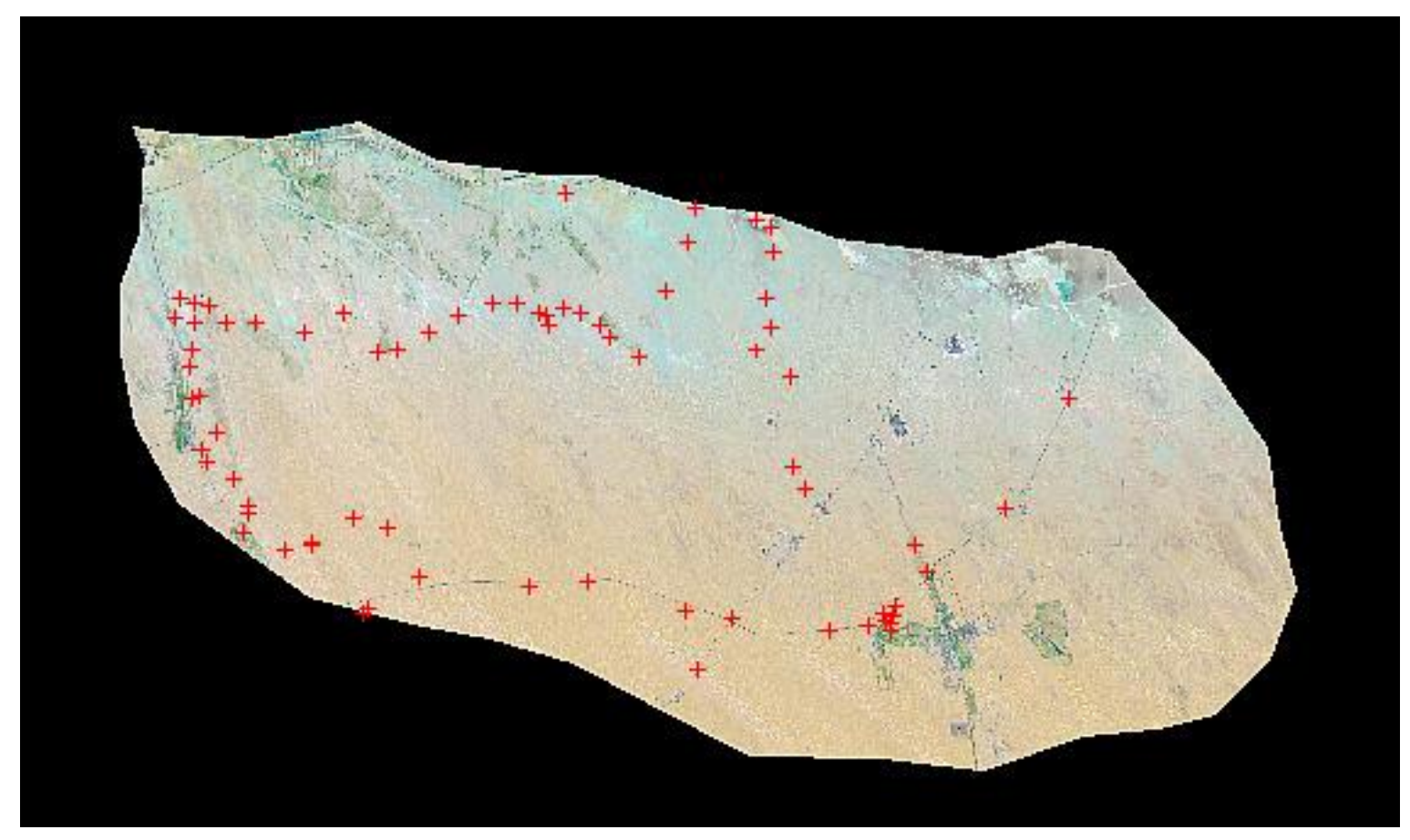

Figure 2: Landsat false color of study area and soil ground sampling locations 


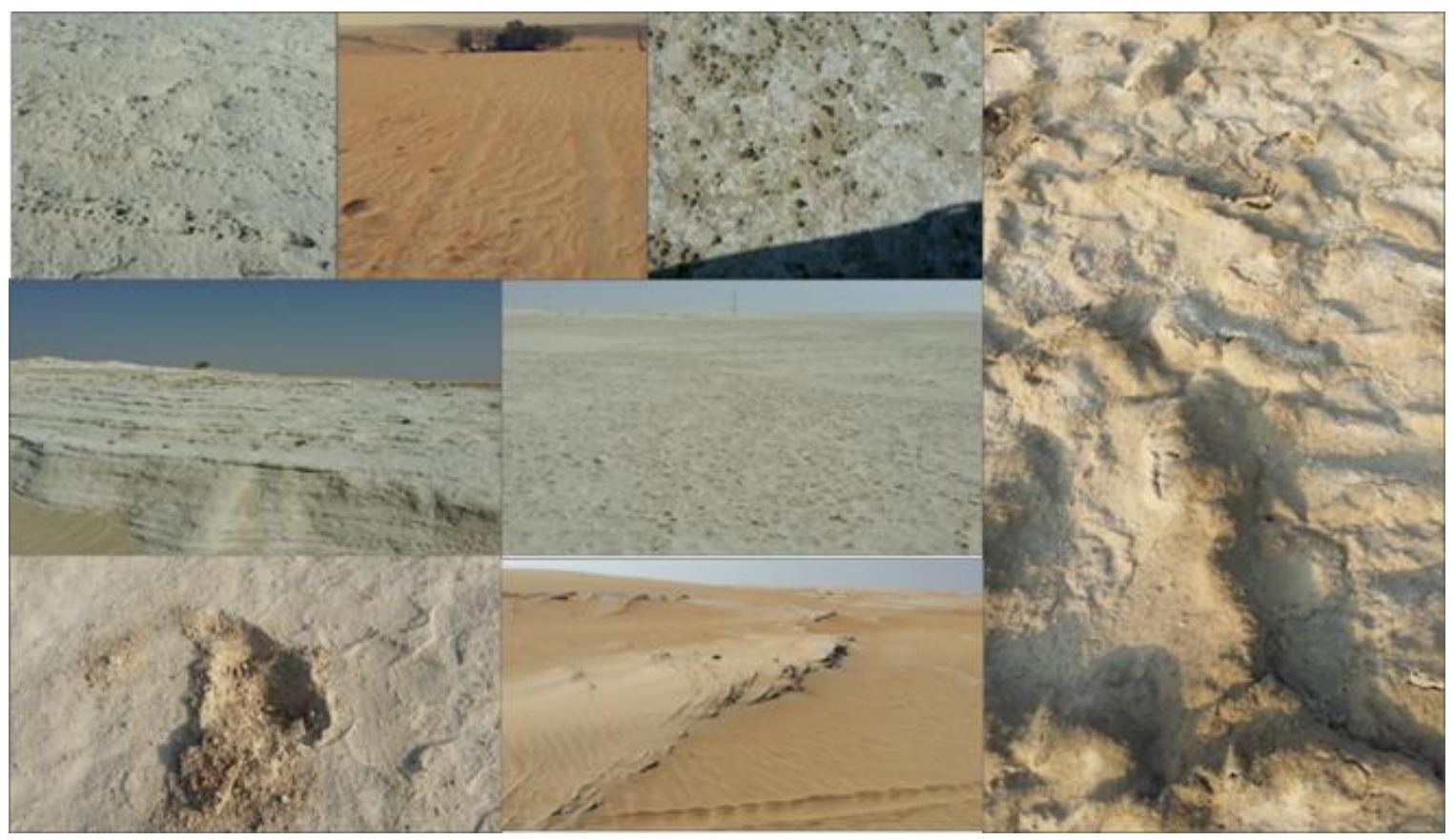

Figure 3: Saline soils and sabkha sampling sites

The sample locations were marked using global positioning system (GPS). 89 samples were acquired with the help of a small spade [39] by scrapping off the top surface of the sand/soil to avoid erosion affects. These samples were stored in labelled airlock bags to be brought to the lab for salinity testing. In the lab, each sample was air-dried at room temperature and ground with a geologic hammer for homogeneity, prior to testing, as per the standard procedure [39], [41].

\section{Lab Analysis}

A solution of 1:2 sample and deionized water [41], respectively, was prepared for each sample after thorough mixing and filtration, Figure 4(a-c), to measure the amount of soluble salts in the soil sample using electrical conductivity meter. Electrical conductivity measurement is the most commonly used characteristic for determining the soil salinity [42], [43]. Once the samples were ready for testing, the samples were poured in washed plastic bottles and tested for EC using ExStik EC 400, a handheld, multi range self-calibrated sensor which measures conductivity in the ranges of ( 0 to $199.9 \mu \mathrm{S} / \mathrm{cm}, 200$ to $1999 \mu \mathrm{S} / \mathrm{cm}, 2.00$ to $19.99 \mathrm{mS} / \mathrm{cm})$. For all salinity values, greater than the range of EC meter, the sample was further diluted, and the final salinity values were calculated by the formula: 


\section{$\frac{\text { Final volume }}{\text { Original Volume }} \times$ Salinity}

Where Final Volume was the volume of sample solution after dilution with deionized water and Original Volume was the initial volume of solution at the time of preparation.

The obtained salinity results were tabulated and compared with the Soil Test Handbook for Georgia (Kissel and Sonon, 2008) [41] of soil salinity classification, Table 1 . The comparison revealed that out of the total 89 samples, 41 were falling in the ranking of excessively high salinity (> $2 \mathrm{dS} / \mathrm{m}$ ) (Electrical Conductivity Units: $\mathrm{mS} / \mathrm{cm}=\mathrm{dS} / \mathrm{m}$ (http://www.environment.nsw.gov.au/salinity/basics/units.htm)). It is worth stating that within the scientific literature, that all the soil salinity scales encountered had been developed with respect to soils related to agriculture and plant growth and none accounted for salinity ranges, such as those of very strongly high saline soils and sabkha.
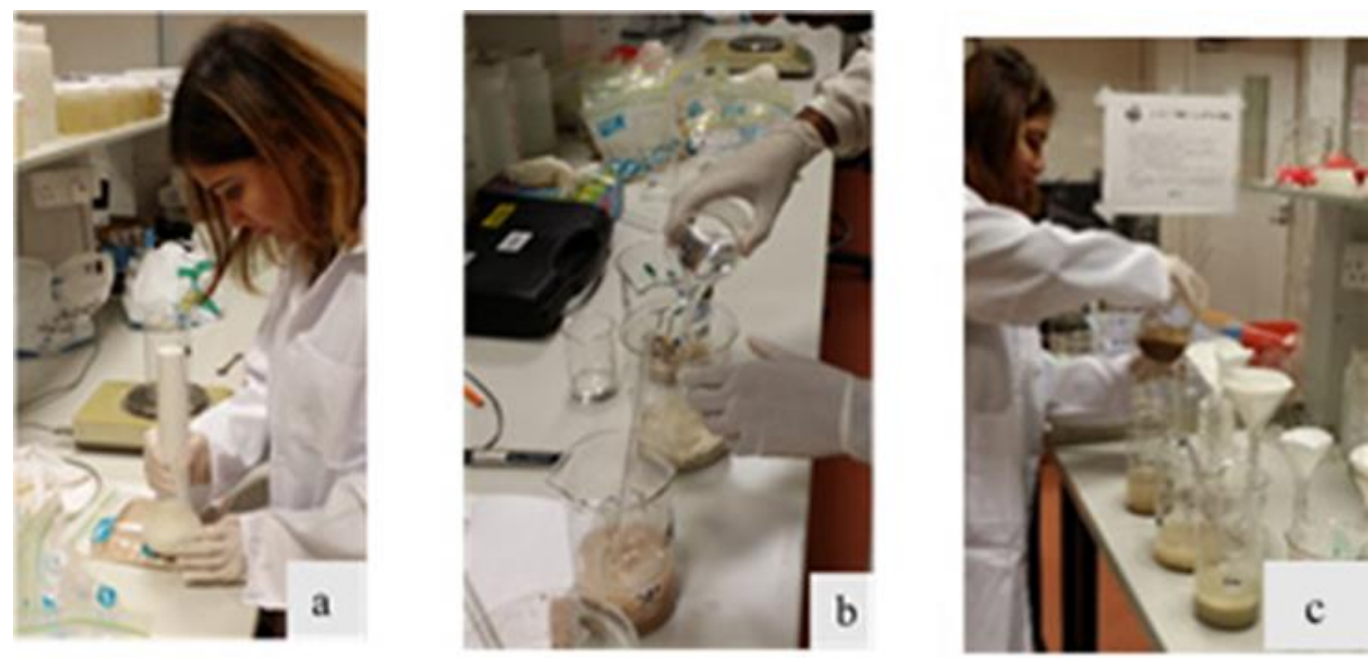

Figure 4: a) Sample grounding, b) Solution preparation, c) Filtration prior to testing 
Table 1: Kissel and Sonon (2008) Soil Salinity Classes

\begin{tabular}{|l|c|}
\hline Soil Salinity Class & EC Salinity Measure (dS/m) \\
\hline Non-Saline & $0-0.15$ \\
\hline Slightly Saline/Low Salinity & $0.15-0.50$ \\
\hline Moderately Saline/Medium Salinity & $0.51-1.25$ \\
\hline Strongly Saline/High Salinity & $1.26-1.75$ \\
\hline Very High Salinity & $1.76-2.00$ \\
\hline Excessively High Salinity & $>2.00$ \\
\hline
\end{tabular}

\section{Satellite Data}

The satellite data used in this study comes from the Landsat 8 OLI collected over the study area. The images cover paths 161 row 43 and path 161 row 44 collected on October $5^{\text {th }} 2016$. These two scenes were chosen for their coverage over the study area, clarity and zero cloud coverage.

\section{Methodology}

\section{Atmospheric Correction}

The initial image processing investigation was to perform atmospheric correction for the Landsat 8 OLI data. This was carried out using the ATCOR algorithm within the GEOMATICA PCI software [44]. Inputs to the atmospheric correction algorithm are shown in Table 2.

Table 2: Input parameters for ATCOR atmospheric correction algorithm

\begin{tabular}{|l|c|}
\hline Terrain Elevation & $0.065 \mathrm{~km}$ \\
\hline Sensor Elevation & $705 \mathrm{~km}$ \\
\hline
\end{tabular}




\begin{tabular}{|l|c|}
\hline Local Time of Acquisition & $6: 53: 01$ \\
\hline Date of Acquisition & $10 / 5 / 2016$ \\
\hline Solar Zenith Angle & 35.407513 \\
\hline Solar Azimuth Angle & 143.6655391 \\
\hline Atmospheric model & Dry \\
\hline Aersol model & Desert \\
\hline Horizontal visibility & $30 \mathrm{~km}$ \\
\hline Water Vapour & $0.75(\mathrm{~g} \mathrm{~cm}-2)$ \\
\hline
\end{tabular}

Once the atmospheric correction process was finalized, the Landsat 8 OLI digital number values (DN) were converted into their corresponding ground reflectance values. Using the field measured GPS the location of each soil sampling location was identified in the satellite images and their corresponding spectral reflectance values were extracted. It is worth noting here that only the spectral reflectance values of bands 2 to 7 are used in this study.

\section{Index Development}

To identify and observe how saline soils spectral reflectance differs from non-saline soils, it was necessary to plot the spectral reflectance of various levels of soil salinities. This is believed to aid in the process of developing a soil salinity index particularly suited for desert soils. Figures 5 and 6 show the spectral reflectance of 5 different soils with varying levels of salinities.

From Figures 5 and 6 it is interesting to observe that all soils, with their varying levels of salinities, peak in their reflectance at the first short-wave infra-red reflectance band (1.57 - $1.65 \mu \mathrm{ms})$. Saline soils have higher reflectance values within the visible and near-infra-red parts of the spectrum in comparison to non-saline soils. This is likely due to the high intensity of reflectance from such surfaces, particularly, due to the 
whitish color of salt covering a saline pixel within the study area. One key noticeable difference in the spectral reflectance between saline and non-saline soils is within the second short-wave infra-red band (2.11 - $2.29 \mu \mathrm{ms})$. Saline soils reflectance at this band is extremely low in comparison to non-saline soils suggesting strong absorption due to salt presence. Figure 6 is a close-up of saline and non-saline soils reflectance in the NIR-SWIR regions and demonstrates this further.

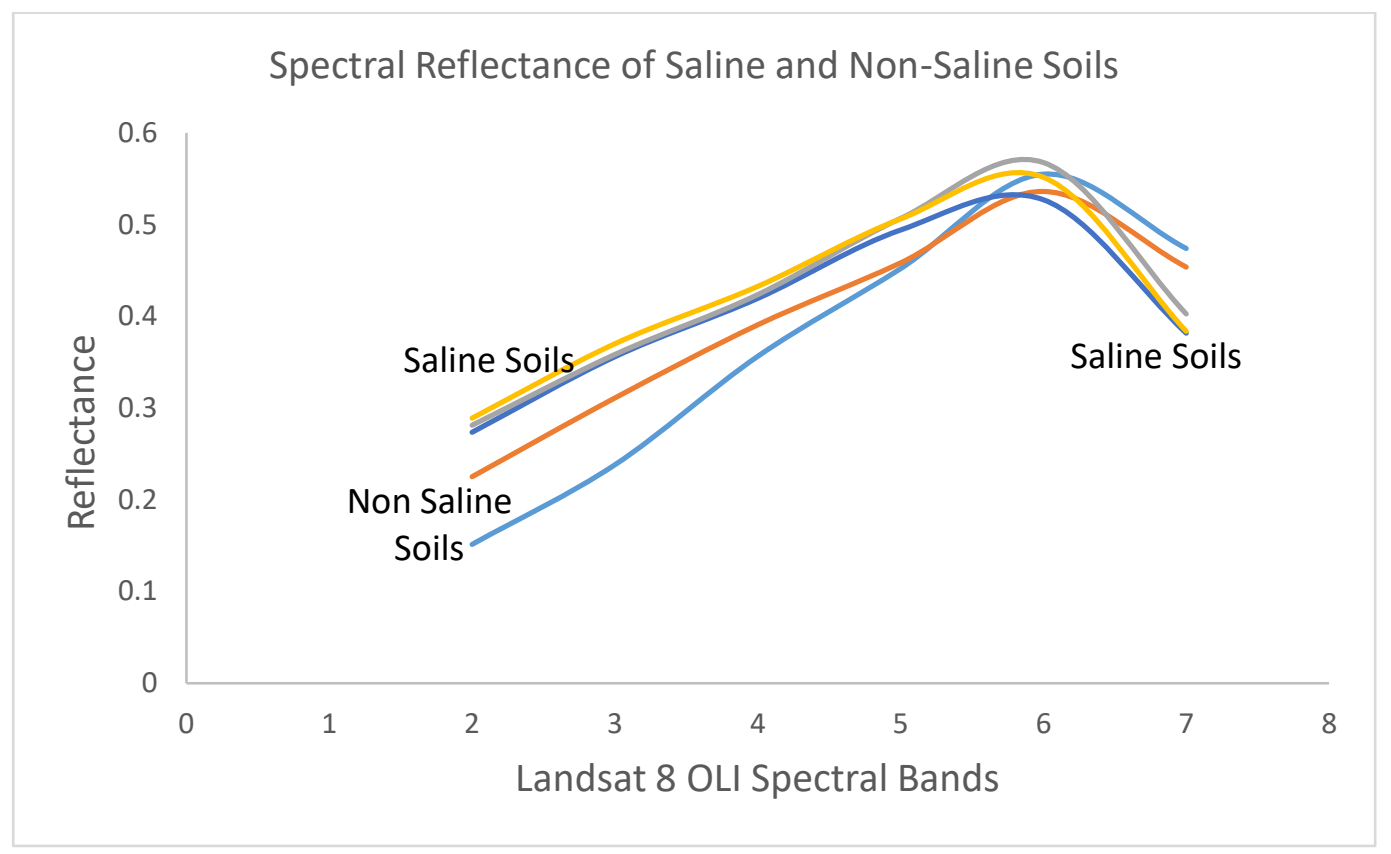

Figure 5: Spectral Reflectance of Saline and Non-Saline Soils 


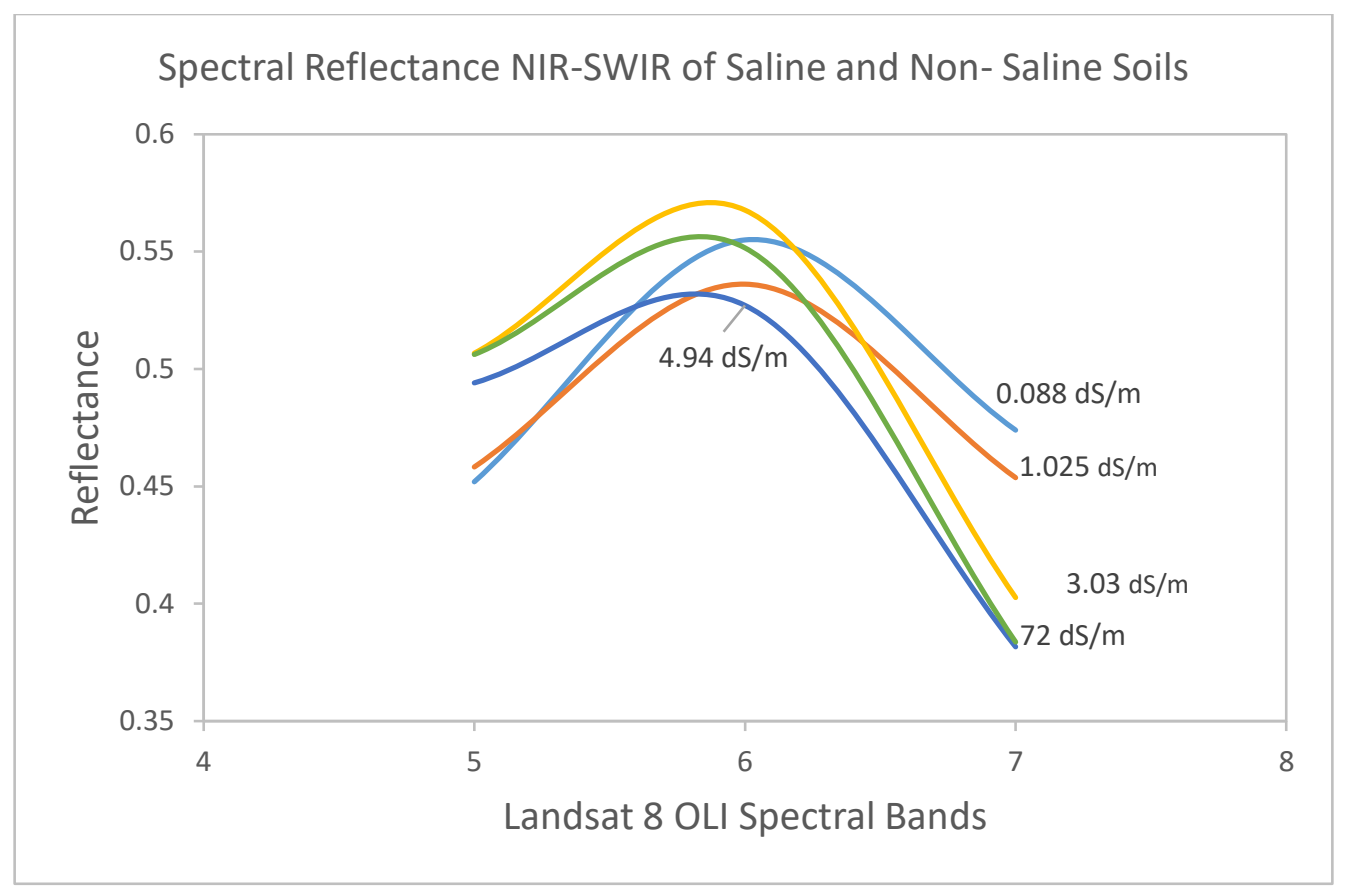

Figure 6: Spectral Reflectance NIR-SWIR of Saline and Non-Saline Soils

While both saline and non-saline soils all have varying degrees of response in the VIS-NIR-SWIR regions, it appears that a key difference between the two is within the NIR-SWIR regions. For this, the study is developing a NIR-SWIR index (NSI), that takes into account this difference in spectral response.

\section{NIR-SWIR Salinity Index $($ NSI $)=\frac{(S W I R 1-S W I R 2)}{(S W I R 1-N I R)}$}

It should be expected that this index would be significantly higher than unity in its magnitude for saline soils and quite low in magnitude for non-saline soils. High salinity soils will portray higher values for the term SWIR 1 - SWIR 2 and lower values for SWIR1 - NIR leading to index values higher than unity. To assess the accuracy of this index in estimating soil salinity it is imperative to compare it with some of the widely-used salinity indices such as the normalized difference salinity index (NDSI) [34], the Salinity Index ASTER (SI_ASTER) [45] and the Soil Salinity and Sodicity Index -1 and Index-2 (SSSI-1 and SSSI-2) [45]. 


\section{Empirical Models Development}

Mathematical and statistical modelling of the interactions between the incident solar electromagnetic radiation and physical and biophysical surface characteristics has been an active area of research in remote sensing. Statistical and mathematical models have been developed to model vegetation canopies [47], soil moisture [48] and soil salinity [46], [49]. A widely used technique in the estimation of soil salinity in arid and semi-arid regions is the application of empirical and semi-empirical soil salinity models [46], [49]. Research in this area has resulted in considerable improvements in estimating soil salinity, its spatial distribution and the interaction between electromagnetic radiation and saline soils.

In attempt to develop a new empirical model the NSI values for the field soil sampling locations were regressed with the lab estimated salinity EC measurements. Various regression models were developed, and the exponential relation portrayed the highest R-square values. The exponential relation is ideal with

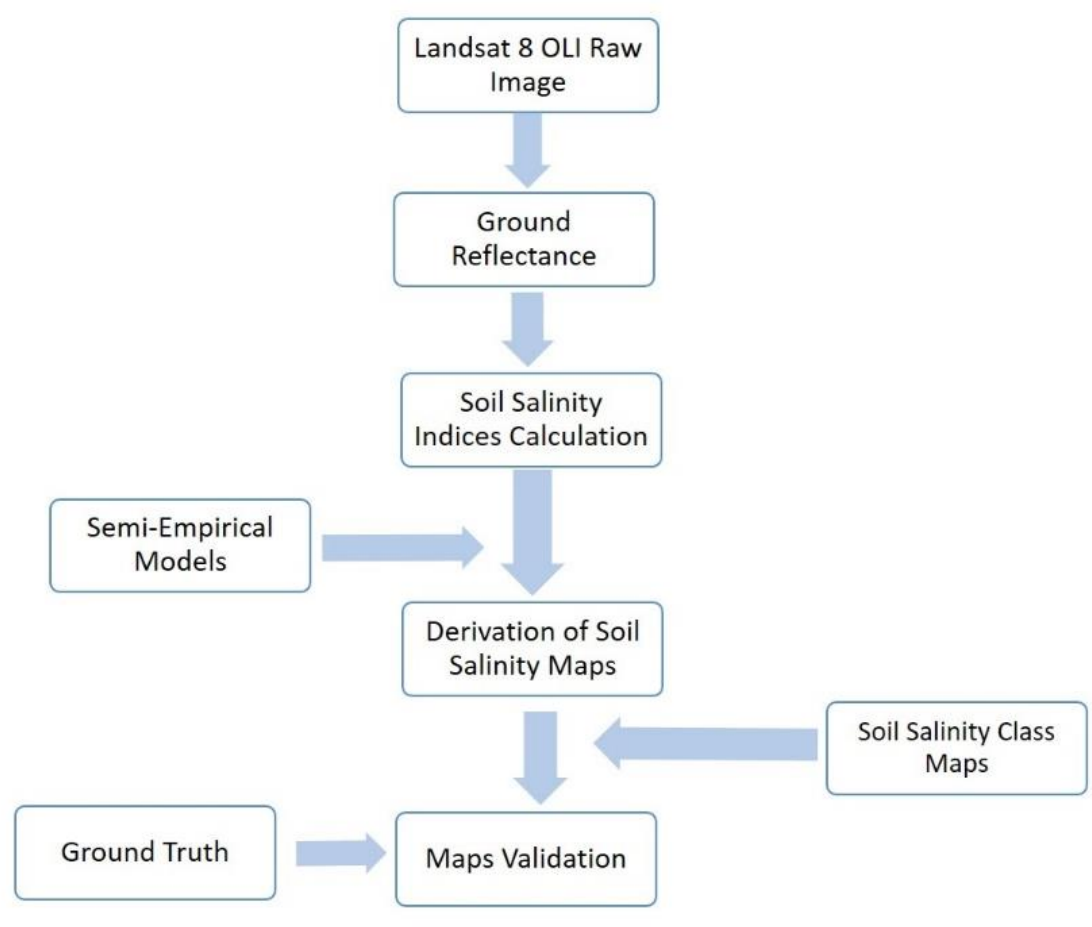

Figure 7: Soil salinity class mapping methodology 
soil salinity indices due to their low saturation levels (Bannari, personal communications). The developed semi-empirical models were later applied for the Landsat 8 OLI for generating soil salinity and soil salinity class maps. The overall methodology followed in this study has been summarized in Figure 7.

\section{Results and Discussion}

Statistical exponential relationships were developed between field measured soil salinity and the five indices mentioned previously. Figures 8 through 12 show the generated models between salinity indices and the field measured EC salinity values.

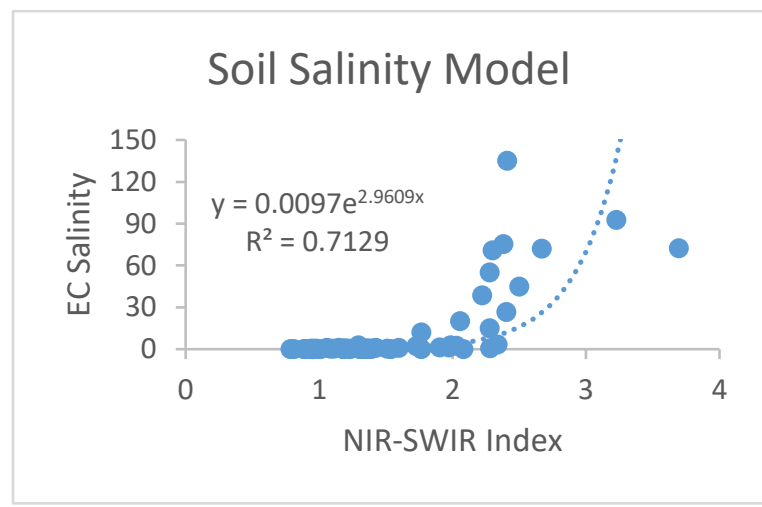

Figure 8: NSI Soil Salinity Model

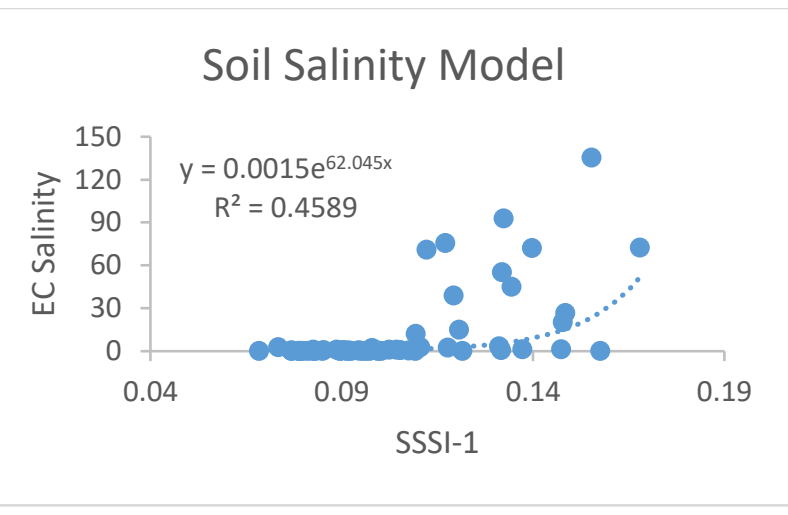

Figure 9: SSSI-1 Soil Salinity Model

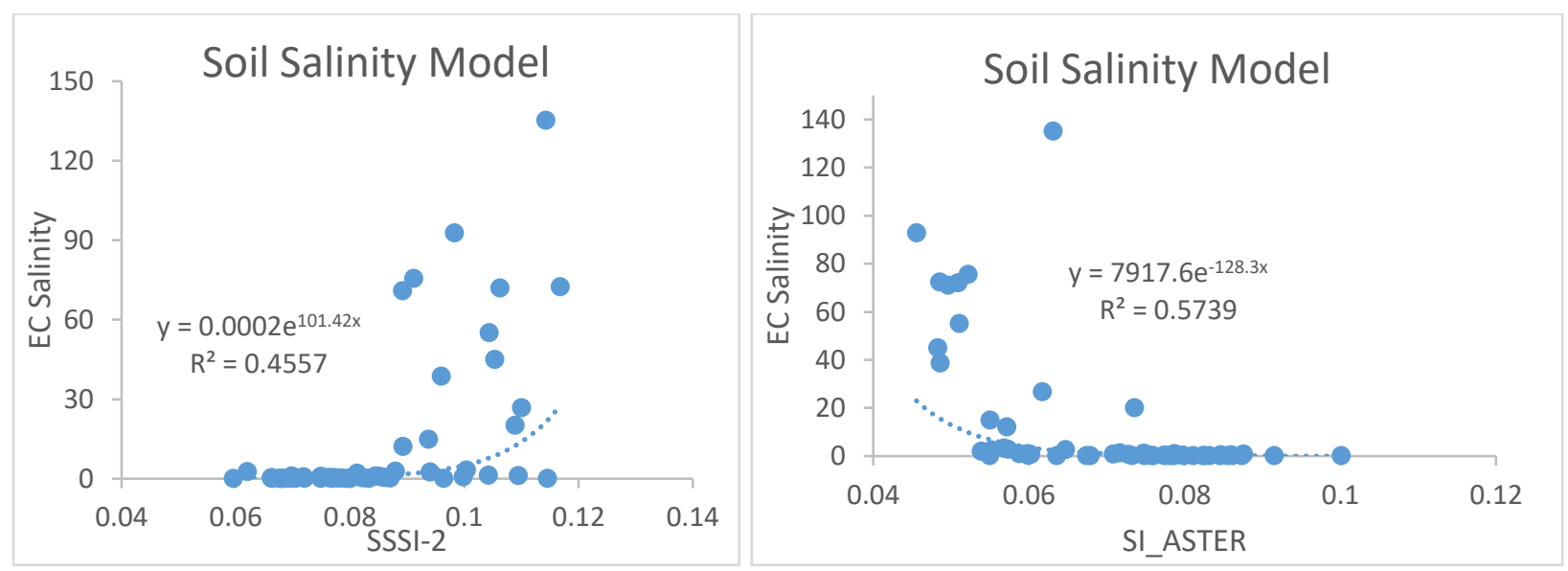

Figure 10: SSSI-2 Soil Salinity Model

Figure 11: SI_ASTER Soil Salinity Model 


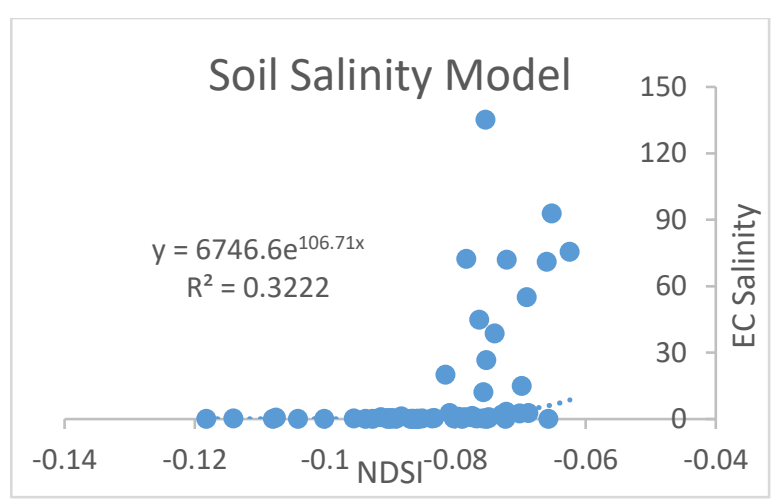

Figure 12: NDSI Soil Salinity Model

The NSI model outperformed all other salinity indices models and showed the highest R-square (0.71) relationship between the EC salinity measures and the NSI. The SI_ASTER model showed and R-square value of 0.57 followed by both the SSSI-1 and SSSI-2 (0.45). The NDSI model performed the worst portraying the relationship strength of only 0.32 . Table 3 summarizes the modeling results.

Table 3: Salinity Models

\begin{tabular}{|l|c|c|}
\hline Salinity Index & Model & R-square \\
\hline NSI Model & $\mathrm{y}=0.0097 \mathrm{e}^{2.9609 \mathrm{x}}$ & 0.71 \\
\hline SSSI-1 Model & $\mathrm{y}=0.0015 \mathrm{e}^{62.045 \mathrm{x}}$ & 0.46 \\
\hline SSSI-2 Model & $\mathrm{y}=0.0002 \mathrm{e}^{101.42 \mathrm{x}}$ & 0.46 \\
\hline SI_ASTER Model & $\mathrm{y}=7917.6 \mathrm{e}^{-128.3 \mathrm{x}}$ & 0.57 \\
\hline NDSI Model & $\mathrm{y}=6746.6 \mathrm{e}^{106.71 \mathrm{x}}$ & 0.32 \\
\hline
\end{tabular}

$\mathrm{x}$ refers to the index

Using the developed statistical models, it will be possible to generate soil salinity class maps for the study area. This research introduces the concept of salinity level categories map for displaying the overall salinity within the study area, instead of actual model estimations of salinity per image pixel. The soil salinity class maps developed here categorize model pixel estimated salinities as per the Kissel and Sonon (2008)[41] 
soil salinity classification. For each salinity level class, a range of salinity values as predicted by the models are associated with a particular class type ranging from non-saline soils class to very strongly saline class are given in Table 4.

Table 4: Verification Field Samples Distribution

\begin{tabular}{|l|c|}
\hline \multicolumn{1}{|c|}{ Salinity Class } & $\begin{array}{c}\text { Number of Field } \\
\text { Samples }\end{array}$ \\
\hline Non-Saline Soils & 4 \\
\hline Low Salinity & 9 \\
\hline Medium Salinity & 2 \\
\hline High Salinity & 3 \\
\hline Very High Salinity & 2 \\
\hline Excessively High Salinity - Sabkha & 10 \\
\hline
\end{tabular}

In thematic mapping from remotely sensed data, the term accuracy is used typically to express the degree of 'correctness' of a map or classification [50]. Any map that is derived from a remote sensing classification process should provide some measure of its accuracy to be considered reliable. Generally, classification accuracy refers to the degree to which a map derived from a remote sensing classification process matches real world information. In this study, a total of 30 field samples were used for the verification and accuracy assessment of each salinity map developed. The verification process composed of identifying in which salinity class does each field measurement point falls within each map based on its salinity EC measurements. Table 4 shows the distribution of the verification points among the different salinity classes within the study area. 


\section{Maps Verification}

In total 30 field sample points were used for the verification of each map. The verification process composed of identifying the class in which each point fell within each map based on its salinity/ EC measurements. Figures 13 - 17 show five salinity class maps for each model, along with classification confusion matrix for each map to provide a measure of map accuracy, tables 5-9.

\section{NSI Salinity Map}

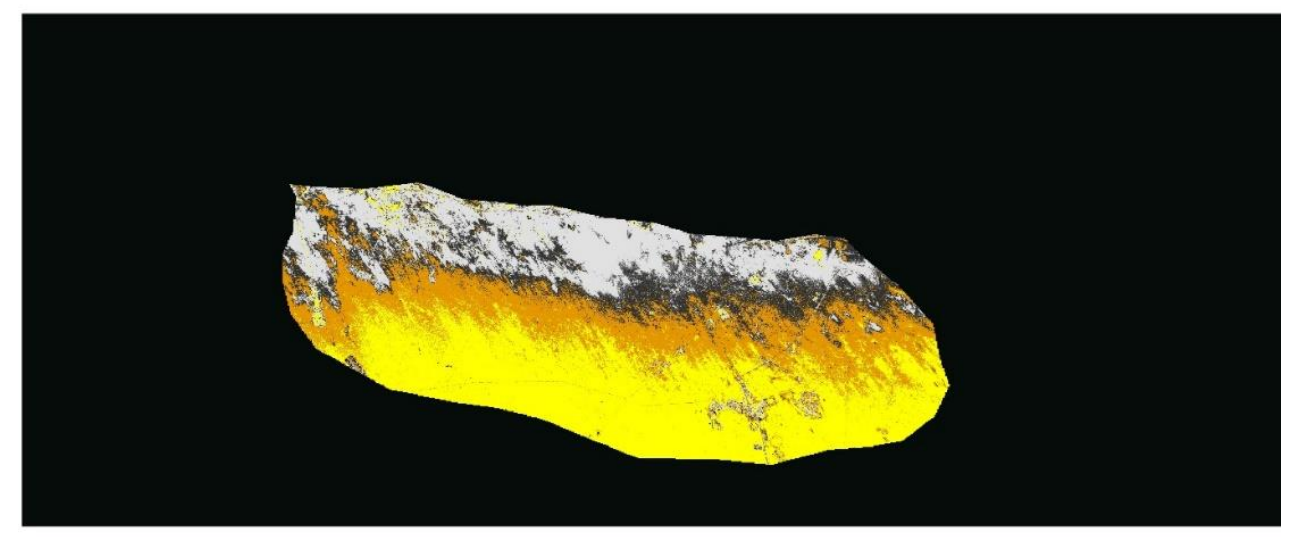

\section{Legend}

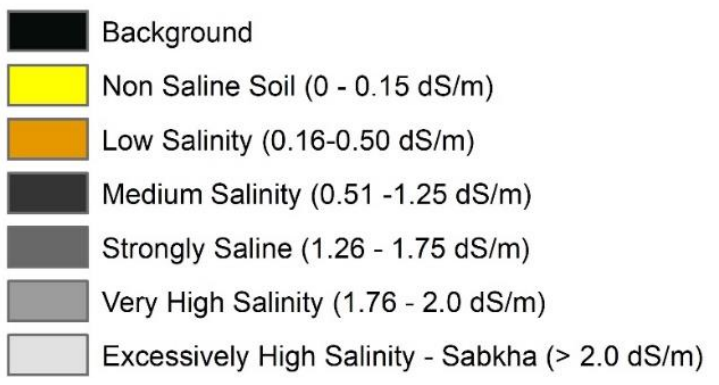

Figure 13: NSI Soil Salinity Map 
Table 5: NSI Map Confusion Matrix

\begin{tabular}{|l|c|c|c|c|c|c|}
\hline \multicolumn{1}{|c|}{ Salinity Class } & $\begin{array}{c}\text { Non- } \\
\text { Saline }\end{array}$ & $\begin{array}{c}\text { Low } \\
\text { Salinity }\end{array}$ & $\begin{array}{c}\text { Medium } \\
\text { Salinity }\end{array}$ & $\begin{array}{c}\text { High } \\
\text { Salinity }\end{array}$ & $\begin{array}{c}\text { Very } \\
\text { High } \\
\text { Salinity }\end{array}$ & $\begin{array}{c}\text { Excessively } \\
\text { High Salinity - } \\
\text { Sabkha }\end{array}$ \\
\hline & & & & & & \\
\hline Non-Saline & 2 & 2 & 0 & 0 & 0 & 0 \\
\hline Low Salinity & 3 & 3 & 3 & 0 & 0 & 0 \\
\hline Medium Salinity & 0 & 0 & 2 & 0 & 0 & 0 \\
\hline High Salinity & 0 & 0 & 0 & 2 & 0 & 1 \\
\hline Very High Salinity & 0 & 0 & 0 & 0 & 0 & 2 \\
\hline $\begin{array}{l}\text { Excessively High Salinity - } \\
\text { Sabkha }\end{array}$ & 0 & 0 & 0 & 0 & 1 & 9 \\
\hline Overall Accuracy & & & & & & $60 \%$ \\
\hline
\end{tabular}

\section{SSSI-1 Salinity Map}

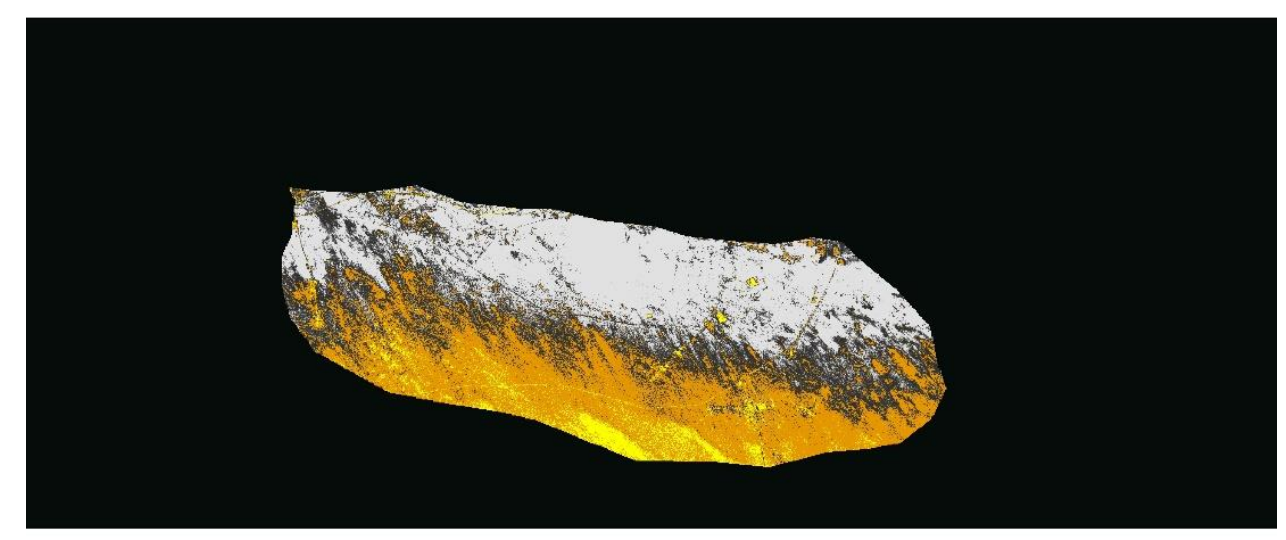

\section{Legend}

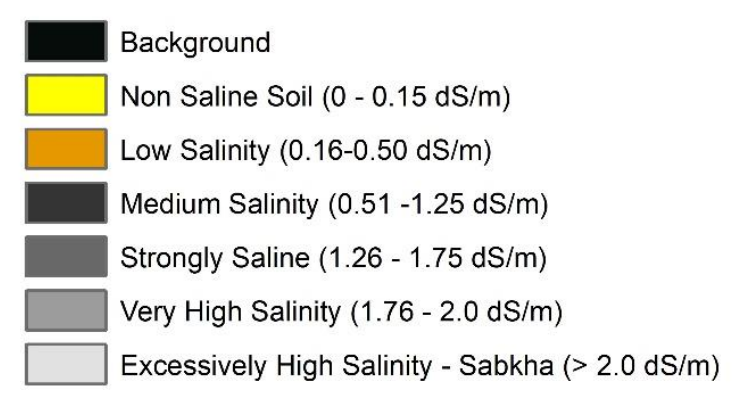

Figure 14: SSSI-1 Soil Salinity Map 
Table 6: SSSI-1 Map Confusion Matrix

\begin{tabular}{|l|c|c|c|c|c|c|}
\hline \multicolumn{1}{|c|}{ Salinity Class } & $\begin{array}{c}\text { Non- } \\
\text { Saline }\end{array}$ & $\begin{array}{c}\text { Low } \\
\text { Salinity }\end{array}$ & $\begin{array}{c}\text { Medium } \\
\text { Salinity }\end{array}$ & $\begin{array}{c}\text { High } \\
\text { Salinity }\end{array}$ & $\begin{array}{c}\text { Very } \\
\text { High } \\
\text { Salinity }\end{array}$ & $\begin{array}{c}\text { Excessively } \\
\text { High } \\
\text { Salinity - } \\
\text { Sabkha }\end{array}$ \\
\hline Non-Saline & & & & & & \\
\hline Low Salinity & 0 & 4 & 0 & 0 & 0 & 0 \\
\hline Medium Salinity & 0 & 0 & 1 & 0 & 0 & 1 \\
\hline High Salinity & 0 & 0 & 0 & 1 & 0 & 2 \\
\hline Very High Salinity & 0 & 0 & 0 & 0 & 0 & 2 \\
\hline $\begin{array}{l}\text { Excessively High Salinity - } \\
\text { Sabkha }\end{array}$ & 0 & 0 & 0 & 0 & 2 & 8 \\
\hline Overall Accuracy & & & & & & $50 \%$ \\
\hline
\end{tabular}




\section{SSSI-2 Salinity Map}

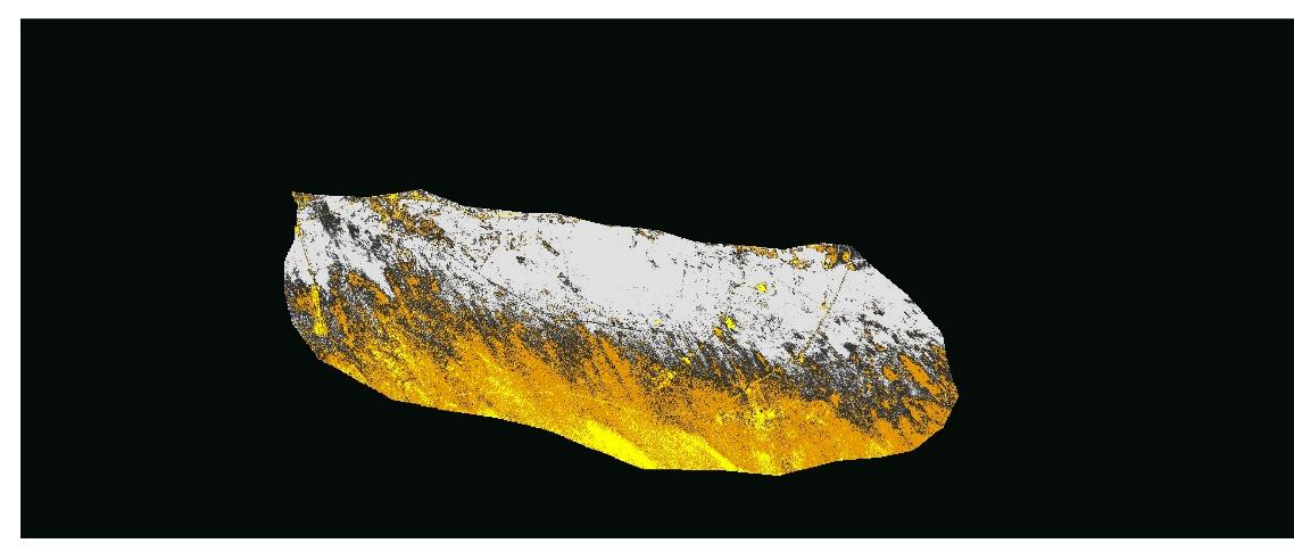

\section{Legend}

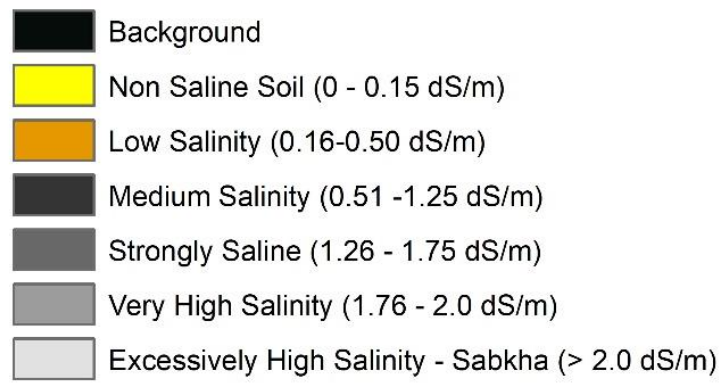

Figure 15: SSSI-2 Soil Salinity Map

Table 7: SSSI-2 Map Confusion Matrix

\begin{tabular}{|l|c|c|c|c|c|c|}
\hline \multicolumn{1}{|c|}{ Salinity Class } & $\begin{array}{c}\text { Non- } \\
\text { Saline }\end{array}$ & $\begin{array}{c}\text { Low } \\
\text { Salinity }\end{array}$ & $\begin{array}{c}\text { Medium } \\
\text { Salinity }\end{array}$ & $\begin{array}{c}\text { High } \\
\text { Salinity }\end{array}$ & $\begin{array}{c}\text { Very } \\
\text { High } \\
\text { Salinity }\end{array}$ & $\begin{array}{c}\text { Excessively } \\
\text { High Salinity - } \\
\text { Sabkha }\end{array}$ \\
\hline & & & & & & \\
\hline Non-Saline & 0 & 4 & 0 & 0 & 0 & 0 \\
\hline Low Salinity & 2 & 4 & 3 & 0 & 0 & 0 \\
\hline Medium Salinity & 0 & 1 & 1 & 0 & 0 & 0 \\
\hline High Salinity & 0 & 0 & 0 & 1 & 0 & 2 \\
\hline Very High Salinity & 0 & 0 & 0 & 0 & 0 & 2 \\
\hline $\begin{array}{l}\text { Excessively High Salinity - } \\
\text { Sabkha }\end{array}$ & 0 & 0 & 1 & 0 & 0 & 9 \\
\hline Overall Accuracy & & & & & & $50 \%$ \\
\hline
\end{tabular}




\section{SI-ASTER Salinity Map}

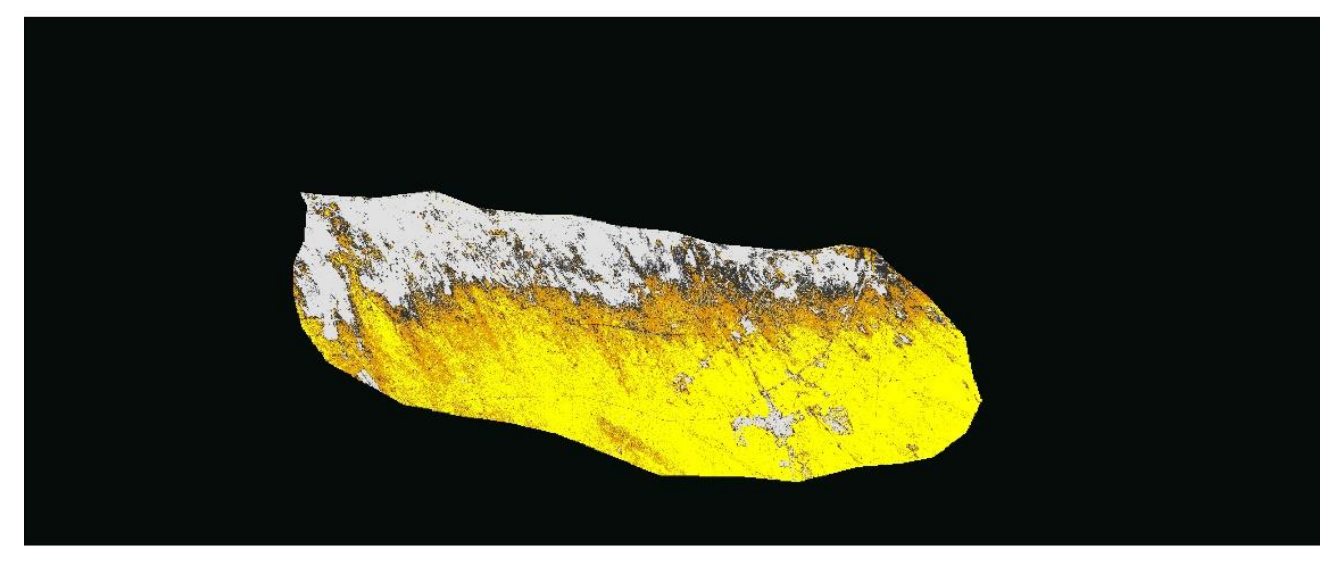

\section{Legend}

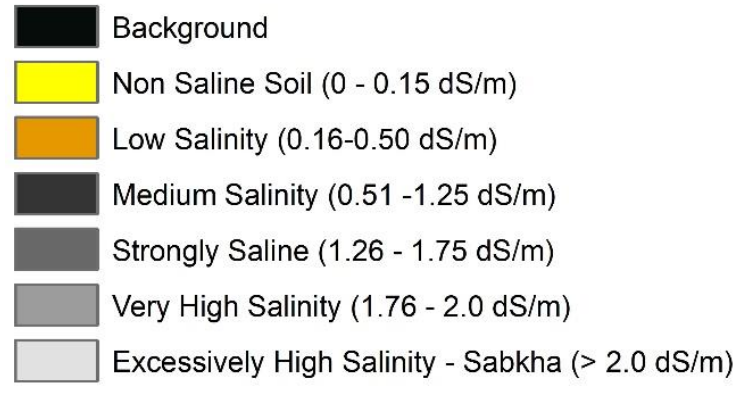

Figure16: SI_ASTER Soil Salinity Map

Table 8: SI_ASTER Map Confusion Matrix

\begin{tabular}{|l|c|c|c|c|c|c|}
\hline \multicolumn{1}{|c|}{ Salinity Class } & $\begin{array}{c}\text { Non- } \\
\text { Saline }\end{array}$ & $\begin{array}{c}\text { Low } \\
\text { Salinity }\end{array}$ & $\begin{array}{c}\text { Medium } \\
\text { Salinity }\end{array}$ & $\begin{array}{c}\text { High } \\
\text { Salinity }\end{array}$ & $\begin{array}{c}\text { Very } \\
\text { High } \\
\text { Salinity }\end{array}$ & $\begin{array}{c}\text { Excessively } \\
\text { High Salinity - } \\
\text { Sabkha }\end{array}$ \\
\hline & & & & & & \\
\hline Non-Saline & 3 & 0 & 0 & 1 & 0 & 0 \\
\hline Low Salinity & 3 & 4 & 0 & 0 & 0 & 2 \\
\hline Medium Salinity & 0 & 1 & 1 & 0 & 0 & 0 \\
\hline High Salinity & 0 & 0 & 1 & 0 & 0 & 2 \\
\hline Very High Salinity & 0 & 0 & 1 & 0 & 0 & 1 \\
\hline $\begin{array}{l}\text { Excessively High Salinity - } \\
\text { Sabkha }\end{array}$ & 0 & 3 & 0 & 0 & 0 & 7 \\
\hline Overall Accuracy & & & & & & $50 \%$ \\
\hline
\end{tabular}




\section{NDSI Salinity Map}

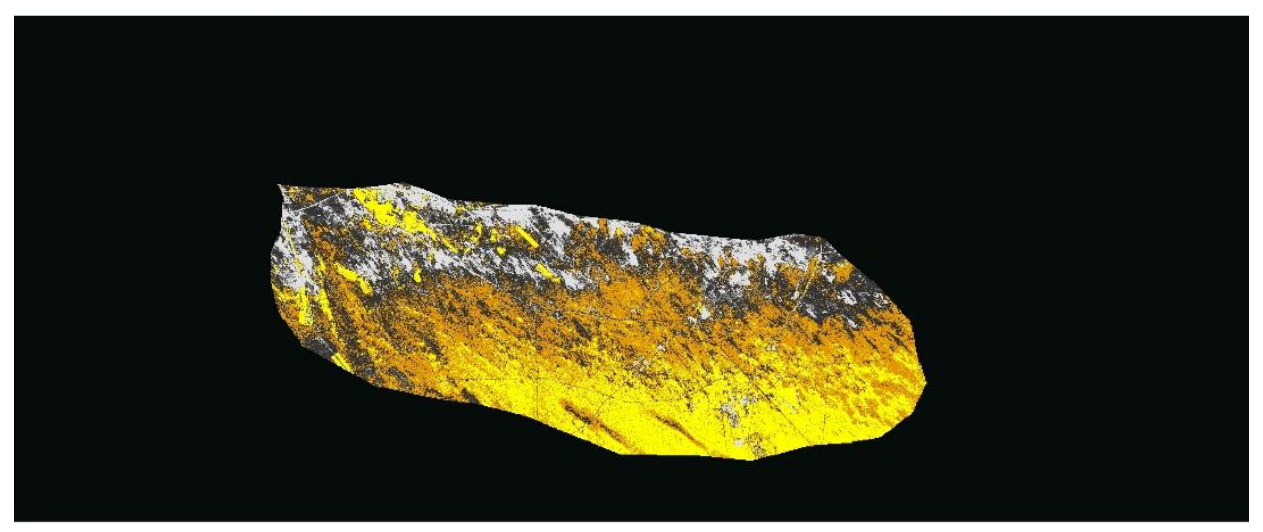

\section{Legend}

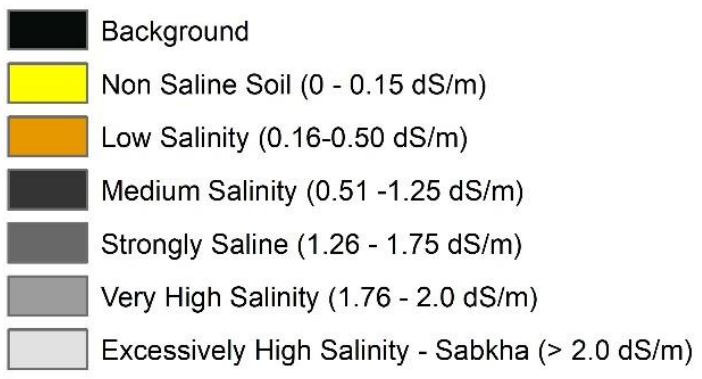

Figure 17: NDSI Soil Salinity Map

Table 9: NDSI Map Confusion Matrix

\begin{tabular}{|l|c|c|c|c|c|c|}
\hline \multicolumn{1}{|c|}{ Salinity Class } & $\begin{array}{c}\text { Non- } \\
\text { Saline }\end{array}$ & $\begin{array}{c}\text { Low } \\
\text { Salinity }\end{array}$ & $\begin{array}{c}\text { Medium } \\
\text { Salinity }\end{array}$ & $\begin{array}{c}\text { High } \\
\text { Salinity }\end{array}$ & $\begin{array}{c}\text { Very } \\
\text { High } \\
\text { Salinity }\end{array}$ & $\begin{array}{c}\text { Excessively } \\
\text { High Salinity - } \\
\text { Sabkha }\end{array}$ \\
\hline & & & & & & \\
\hline Non-Saline & 2 & 1 & 0 & 0 & 0 & 1 \\
\hline Low Salinity & 2 & 2 & 2 & 1 & 0 & 2 \\
\hline Medium Salinity & 0 & 0 & 0 & 1 & 0 & 1 \\
\hline High Salinity & 0 & 0 & 0 & 1 & 2 & 0 \\
\hline Very High Salinity & 0 & 1 & 0 & 0 & 0 & 1 \\
\hline $\begin{array}{l}\text { Excessively High Salinity - } \\
\text { Sabkha }\end{array}$ & 0 & 0 & 2 & 1 & 0 & 7 \\
\hline Overall Accuracy & & & & & & $40 \%$ \\
\hline
\end{tabular}


The results demonstrated that the NSI based model outperformed all other salinity indices in mapping soil salinity in non-agricultural arid lands. The NSI model yielded a much higher overall map accuracy and demonstrated the ability to strongly distinguish very highly saline soils and sabkha much more accurately. The strength of this model lies in its use of the near-infrared and shortwave infrared spectral information. This information is demonstrating to be a key component in distinguishing between various levels of soil salinity.

The SSSI-1, SSSI-2 and SI_ASTER models equally portrayed the second highest level of overall map accuracy. These indices use similar spectral information, albeit, different mathematical formulation. Its second highest level in accuracy performance further demonstrates that the combination of NIR-SWIR is key in properly mapping extremely highly saline soils. The NDSI based model failed in mapping highly saline soils.

Table 10 (accuracy per class) establishes that the NSI based model performed the best in mapping excessively high saline (sabkhas) soils (90\%) and high saline soils (67\%) in comparison to all other models. While it showed reasonable good accuracy in mapping non-saline soils it failed to predict low saline soils accurately. This failure might likely be due to the slightly low saline soils not having a discriminative spectral response in the NIR-SWIR spectral bands. The NSI model is followed by the SSSI-2 in its ability to map excessively high saline (sabkha) areas (90\%) and high saline soils (33\%). The NDSI based model performed accurately in predicting and mapping medium salinity levels (100\%) and low saline soils (33\%)). 
Table 10: Accuracy per salinity class

\begin{tabular}{|l|c|c|c|c|c|c|}
\hline \multicolumn{1}{|c|}{ Salinity Class } & $\begin{array}{c}\text { Non- } \\
\text { Saline }\end{array}$ & $\begin{array}{c}\text { Low } \\
\text { Salinity }\end{array}$ & $\begin{array}{c}\text { Medium } \\
\text { Salinity }\end{array}$ & $\begin{array}{c}\text { High } \\
\text { Salinity }\end{array}$ & $\begin{array}{c}\text { Very High } \\
\text { Salinity }\end{array}$ & $\begin{array}{c}\text { Excessively High } \\
\text { Salinity - Sabkha }\end{array}$ \\
\hline & & & & & & \\
\hline NSI & $50 \%$ & $33 \%$ & $100 \%$ & $67 \%$ & $0 \%$ & $90 \%$ \\
\hline SSSI-1 & $0 \%$ & $44 \%$ & $50 \%$ & $33 \%$ & $0 \%$ & $80 \%$ \\
\hline SSSI-2 & $0 \%$ & $44 \%$ & $50 \%$ & $33 \%$ & $0 \%$ & $90 \%$ \\
\hline SI-ASTER & $75 \%$ & $44 \%$ & $50 \%$ & $0 \%$ & $0 \%$ & $70 \%$ \\
\hline NDSI & $50 \%$ & $22 \%$ & $0 \%$ & $33 \%$ & $0 \%$ & $70 \%$ \\
\hline
\end{tabular}

The SSSI-1 and SSSI-2 based models in this study demonstrated conflicting results to those shown in [49].

As mentioned formerly, both models did not incorporate the near infrared information, which has been confirmed to be a crucial component in mapping and predicting excessively high salinity (sabkhas). In this particular study area, excessively high salinity (sabkhas) constituted a sizable portion of the total area, and the exclusion of near infrared information lead to this poor performance of these models.

An additional observation from the soil salinity classification maps, is that the spatial distribution of the highly saline and excessively high salinity (sabkhas) soils are mostly located in the northern part in close proximity of the Arabian Gulf waters. This suggests that the high saline soils, very high saline soils and sabkhas in this area were formed due flattening of Pleistocene sand dunes as a result of severe tidal effect and wind erosion accompanied by marine sedimentation up until supratidal environment, in the late Quarternary [37]. Inland dunes eroded down to the level of ground water table by shamal winds (northerly winds) and inter dune spaces concurrently filled up during sea transgression, resulting in carbonate sedimentation. The areas of non-saline soils are mostly located within the southern inland part. This area is mostly composed of aeolian sand and dunes.

The soil salinity classification model used in this study is based on Kissel and Sonon (2008) [41] salinity classification. This model has been developed for agricultural lands and crops yields. It is thus not the optimum model for soil salinity classification in open non-agricultural desert surfaces located in arid and 
semi-arid regions. This suggests the need for developing a new soil salinity classification scheme that is particularly suited for such desert areas.

\section{Conclusions}

Soil salinity is a major environmental problem world-wide due to its adverse effects leading to soil erosions and land degradation. Most of the soil salinity studies have been directed towards its mapping and impact in agricultural lands, however. Soil salinity in desert arid and semi-arid non-agricultural regions is as well a major geo-hazard. This is particularly the case in the study area region of western UAE, where large salt flats have developed due to severe tidal effects and wind erosion in the late Quaternary that led to flattening of Pleistocene sand dunes and was later followed by marine sedimentation. Saline soils in such regions negatively affect urban structures mainly by instigating land subsidence, corrosion and adversely effects ground water quality. The primary objectives of this study are the development of an empirical soil salinity reflectance model that is suited for open desert surfaces with scattered salt flats using the near infra-red and short-wave infra-red portions of the spectrum. The developed model has outperformed, in terms of its mapping accuracy, other salinity indices-based models and has been shown to accurately identify high saline and excessively high salinity (sabkha) soils in comparison to other models. The study results also suggest the need for the development of an additional soil salinity classification system that is more appropriate for open desert non-agricultural soils.

\section{Acknowledgements}

This work was funded by a grant from the Research and Sponsored Projects Office of the United Arab Emirates University under startup grant number 31H106-Research Start-up (4) 2015. 


\section{References}

[1] Metternicht, G.I., \& Zinck, J.A. (2003). Remote sensing of soil salinity: potentials and constraints. Remote sensing of Environment, 85, 1-20

[2] D. P. Shrestha and A. Farshad, "Chapter 13. Mapping Salinity Hazard: An Integrated Application of Remote Sensing and Modeling-Based Techniques," In: G. Met-ternicht and J. A. Zinck, Eds., Remote Sensing of Soil Salinization: Impact on Land Management, CRC Press, Boca Raton, 2008, p. 257. http://dx.doi.org/10.1201/9781420065039.pt3

[3] R. Dwivedi, et al., "5 Generation of Farm-Level Informa-tion on Salt-Affected Soils Using IKONOS-II Multispec-tral Data," In: G. Metternicht and J. Zinck, Eds., Remote Sensing of Soil Salinization: Impact on Land Management, CRC Press, Boca Raton, 2008. http://dx.doi.org/10.1201/9781420065039.ch5

[4] Youssef, A.M., Pradhan, B., Sabtan, A.A., \& El-Harbi, H.M. (2012). Coupling of remote sensing data aided with field investigations for geological hazards assessment in Jazan area, Kingdom of Saudi Arabia. Environmental Earth Sciences, 65, 119-130

[5] Abbas, A., Khan, S., Hussain, N., Hanjra, M.A., \& Akbar, S. (2013). Characterizing soil salinity in irrigated agriculture using a remote sensing approach. Physics and Chemistry of the Earth, Parts A/B/C, 55-57, 43-52

[6] Eldeiry, A.A., \& Garcia, L.A. (2008), Detecting soil salinity in alfalfa fields using spatial modeling and remote sensing. Soil Science Society of America Journal, 72, 201-211

[7] Eldeiry, A.A., \& Garcia, L.A. (2010), Comparison of ordinary kriging, regression kriging, and cokriging techniques to estimate soil salinity using LANDSAT images, Journal of Irrigation and Drainage Engineering 136 (6), 355-364

[8] Jiapaer, G., Chen, X., \& Bao, A. (2011). A comparison of methods for estimating fractional vegetation cover in arid regions. Agricultural and Forest Meteorology, 151, 1698-1710

[9] Rao, B.R.M., Dwivedi, R.S., Venkataratnam, L., Ravishankar, T., Thammappa, S.S., Bhargawa, G.P., \& Singh, A.N. (1991). Mapping the magnitude of sodicity in part of the IndoGangetic plains of Uttar Pradesh, Northern India using Landsat-TM data. International Journal of Remote Sensing, 12, 419-425 
[10] Srivastava, A., Tripathi, N.K., \& Gokhale, K. (1997). Mapping groundwater salinity using IRS-1B LISS II data and GIS techniques. International Journal of Remote Sensing, 18, 2853-2862

[11] Elhag, M. (2016). Evaluation of different soil salinity mapping using remote sensing techniques in arid ecosystems, Saudi Arabia. Journal of Sensors, 2016

[12] Forkuor, G., Hounkpatin, O.K.L., Welp, G., \& Thiel, M. (2017). High Resolution Mapping of Soil Properties Using Remote Sensing Variables in South-Western Burkina Faso: A Comparison of Machine Learning and Multiple Linear Regression Models. PloS one, 12, $\mathrm{e} 0170478$

[13] Lin, B., Cuizhen, W., Shuying, Z., Yuhong, Z., Qiannan, H., \& Yuexiang, W. (2016). Remote Sensing of Soil Alkalinity and Salinity in the Wuyu'er-Shuangyang River Basin, Northeast China. Remote Sensing, 8, 1-16

[14] Abyuelgasim, A., R. Ammad, (2017), Mapping Sabkha Land Surfaces in the United Arab Emirates (UAE) using Landsat 8 Data, Principal Component Analysis and Soil Salinity Information, International Journal of Engineering and Manufacturing 7 (4)

[15] Abdul-Qadir, A.M.H., \& Benni, T.J. (2010). Monitoring and evaluation of soil salinity in term of spectral response using Landsat images and GIS in Mesopotamian plain/Iraq. Journal of Iraqi Desert Studies, 2, 19-32

[16] Darvishsefat, A.A., Damavandi, M.H., Jafari, M., \& Zehtabiyan, G.R. (2000). Assessing of Landsat TM images for using in soil salinity classification. Journal of Desert, 5

[17] Jabbar, M.T., \& Zhou, J. (2012). Assessment of soil salinity risk on the agricultural area in Basrah Province, Iraq: Using remote sensing and GIS techniques. Journal of Earth Science, 23, 881-891

[18] Masoud, A.A. (2014). Predicting salt abundance in slightly saline soils from Landsat ETM + imagery using Spectral Mixture Analysis and soil spectrometry. Geoderma, 217-218, 45-56

[19] Allbed, A., Kumar, L., \& Sinha, P. (2014). Mapping and modelling spatial variation in soil salinity in the Al Hassa Oasis based on remote sensing indicators and regression techniques. Remote Sensing, 6, 1137-1157 
[20] Fallah Shamsi, S.R., Zare, S., \& Abtahi, S.A. (2013). Soil salinity characteristics using moderate resolution imaging spectroradiometer (MODIS) images and statistical analysis. Archives of Agronomy and Soil Science, 59, 471-489

[21] Tompkins, S., Mustard, J.F., Pieters, C.M., \& Forsyth, D.W. (1997). Optimization of endmembers for spectral mixture analysis. Remote Sensing of Environment, 59, 472-489

[22] Zhang, T.-T., Qi, J.-G., Gao, Y., Ouyang, Z.-T., Zeng, S.-L., \& Zhao, B. (2015). Detecting soil salinity with MODIS time series VI data. Ecological Indicators, 52, 480-489

[23] Csillag, F., Pásztor, L., \& Biehl, L.L. (1993). Spectral band selection for the characterization of salinity status of soils. Remote sensing of environment, 43, 231-242

[24] Farifteh, J., Van der Meer, F., Van der Meijde, M., \& Atzberger, C. (2008). Spectral characteristics of salt-affected soils: A laboratory experiment. Geoderma, 145, 196-206

[25] Shepherd, K.D., \& Walsh, M.G. (2002). Development of reflectance spectral libraries for characterization of soil properties. Soil science society of America journal, 66, 988-998

2002

[26] McBratney, A.B., Santos, M.L.M., \& Minasny, B. (2003). On digital soil mapping. Geoderma, 117, 3-52

[27] Douaoui, A.E.K., Nicolas, H., \& Walter, C. (2006). Detecting salinity hazards within a semiarid context by means of combining soil and remote-sensing data. Geoderma, 134, 217-230

[28] Hengl, T., Heuvelink, G.B.M., \& Stein, A. (2004). A generic framework for spatial prediction of soil variables based on regression-kriging. Geoderma, 120, 75-93

[29] Michot, D., Walter, C., Adam, I., \& Guéro, Y. (2013). Digital assessment of soil-salinity dynamics after a major flood in the Niger River valley. Geoderma, 207, 193-204

[30] Metternicht, G., \& Zinck, J.A. (1997). Spatial discrimination of salt-and sodium-affected soil surfaces. International Journal of Remote Sensing, 18, 2571-2586

[31] Abbas, A., \& Khan, S (2007). Using remote sensing technology for appraisal of irrigated soil salinity. In (pp. 2632-2638) 
[32] Ammad, R and Abdelgadir Abuelgasim, 2016, "Comparative analysis of salinity indices for mapping sabkha surfaces in the United Arab Emirates (UAE)." 37th Asian Conference on Remote Sensing: Fostering Resilient Growth in Asia, ACRS 2016; Colombo, Sri Lanka October 16-21, 2016.

[33] Dehni, A., \& Lounis, M. (2012). Remote sensing techniques for salt affected soil mapping: application to the Oran region of Algeria. Procedia Engineering, 33, 188-198

[34] Khan, N.M., Rastoskuev, V.V., Sato, Y., \& Shiozawa, S. (2005). Assessment of hydrosaline land degradation by using a simple approach of remote sensing indicators. Agricultural Water Management, 77, 96-109

[35] Khan, N.M., Rastoskuev, V.V., Shalina, E.V., \& Sato, Y. (2005), Mapping salt-affected soils using remote sensing indicators-a simple approach with the use of GIS IDRISI. In (p. 9)

[36] Allbed, A., \& Kumar, L. (2013). Soil salinity mapping and monitoring in arid and semi-arid regions using remote sensing technology: a review. Advances in remote sensing, 2013

[37] Evans, G., Schmidt, V., Bush, P., \& Nelson, H. (1969). STRATIGRAPHY AND GEOLOGIC HISTORY OF THE SABKHA ABU DHABI, PERSIAN GULF. Sedimentology, 12, 145

[38] Mougenot, B., Pouget, M., \& Epema, G.F. (1993). Remote sensing of salt affected soils. Remote Sensing Reviews, 7, 241-259

[39] Sparks, D.L., Page, A.L., Helmke, P.A., Leoppert, R.H., Soltanpour, P.N., Tabatabai, M.A., Johnston, C.T., \& Sumner, M.E. (1996). Methods of soil analysis-soil science society of America book series. ASA and SSA, Madison, WI, USA

[40] Taghizadeh-Mehrjardi, R., Minasny, B., Sarmadian, F., \& Malone, B.P. (2014). Digital mapping of soil salinity in Ardakan region, central Iran. Geoderma, 213, 15-28

[41] Kissell, D.E., and L. Sonon. 2008. Soil test handbook for Georgia. Univ. Georgia Coop. Ext. Special Bul. 62. 
[42] McNeill, J.D. (1992). Rapid, accurate mapping of soil salinity by electromagnetic ground conductivity meters. Advances in measurement of soil physical properties: Bringing theory into practice, 209-229

[43] Rhoades, J.D. (1993). Electrical conductivity methods for measuring and mapping soil salinity. Advances in agronomy, 49, 201-251

[44] PCI Geomatics (2014) Using PCI Software. Richmond Hill, 540 p.

[45] Al-Khaier, F. (2003). Soil salinity detection using satellite remote sensing. Geo-information Science and Earth Observation, International Institute for Geo-information Science and Earth Observation, 70

[46] Bannari, A., A. M. Guedon, A. El-Harti, F. Z. Cherkaoui, and A. El-Ghmari. (2008). Characterization of slight and moderate saline and sodic soils in irrigated agricultural land using simulated data of ALI (EO-1) sensor. Communications in Soil Science and Plant Analysis, 39:2795-811. doi:10.1080/00103620802432717.

[47] Abuelgasim, A.A., \& Leblanc, S.G. (2011). Leaf area index mapping in northern Canada. International journal of remote sensing, 32, 5059-5076

[48] Zribi, M., Gorrab, A., Baghdadi, N., Lili-Chabaane, Z., \& Mougenot, B. (2014). Influence of radar frequency on the relationship between bare surface soil moisture vertical profile and radar backscatter. IEEE Geoscience and Remote Sensing Letters, 11, 848-852

[49] El-Battay, A., Bannari, A., Hameid, N.A. and Abahussain, A.A. (2017) Comparative Study among Different Semi-Empirical Models for Soil Salinity Prediction in an Arid Environment Using OLI Landsat-8 Data. Advances in Remote Sensing, 6, 23-39.

https://doi.org/10.4236/ars.2017.61002

[50] Foody, G.M. (2002). Status of land cover classification accuracy assessment. Remote sensing of environment, 80, 185-201 